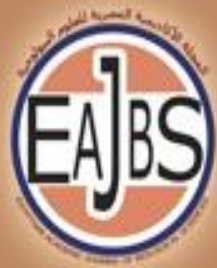

EGYPTIAN ACADEMIC JOURNAL OF
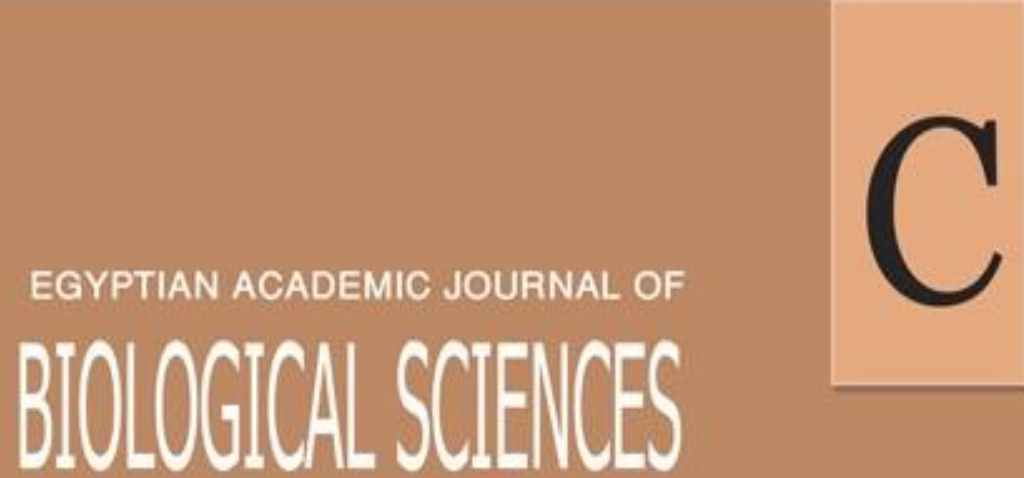

PHYSIOLOGY \& MOLECULARBIOLOGY
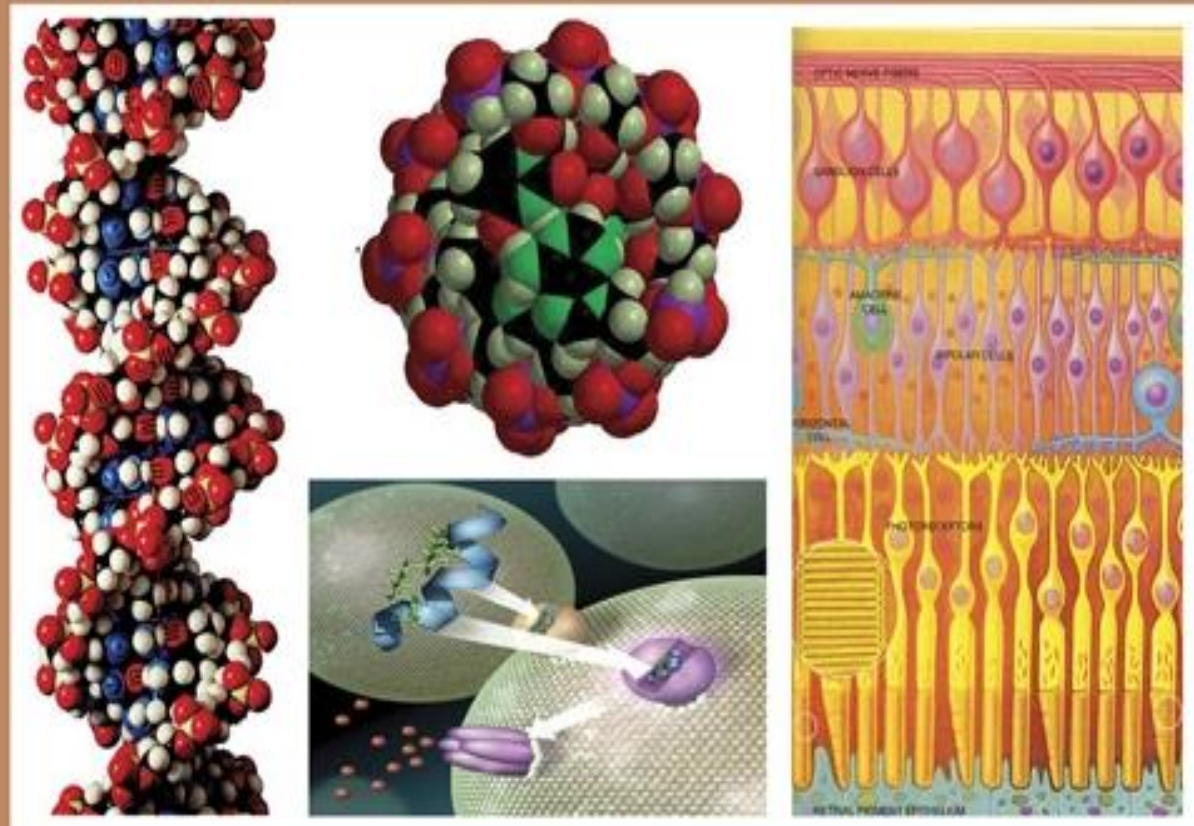

ISSN

2090-0767

WWW.EAJBS.EG.NET

Vol. 13 No. 2 (2021)

Citation: Egypt.Acad.J.Biolog.Sci. ( C.Physiology and Molecular biology) Vol. 13(2) pp63-72 (2021) 
Egypt. Acad. J. Biolog. Sci., 13(2):63-72 (2021)

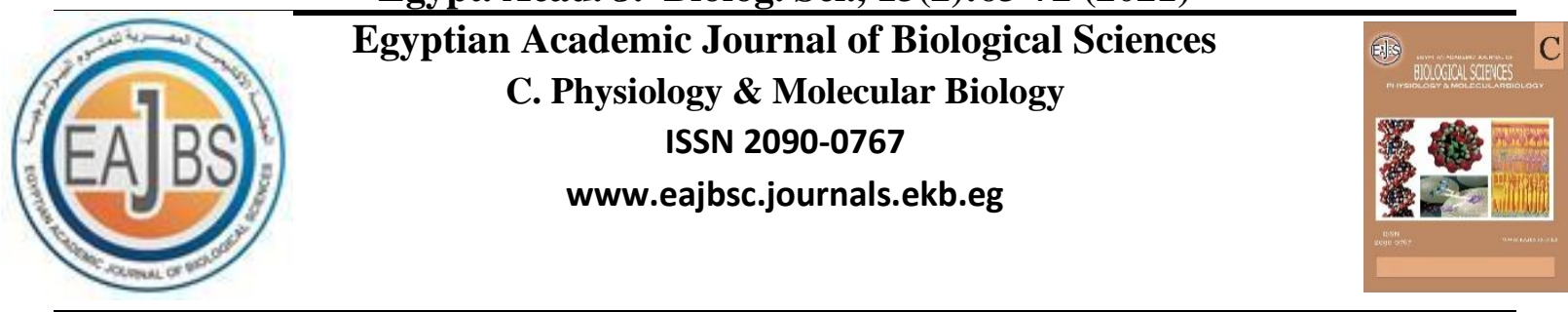

\section{Neurotoxic and Oxidative Stress Impacts in Male Albino Rats Exposed to Single Dose of Abamectin}

Nahas A. A.

Mammalian and Aquatic Toxicology Department, Central Agricultural Pesticides Laboratory, Agricultural Research Center, Giza

*E. Mail : zorosonds@yahoo.com

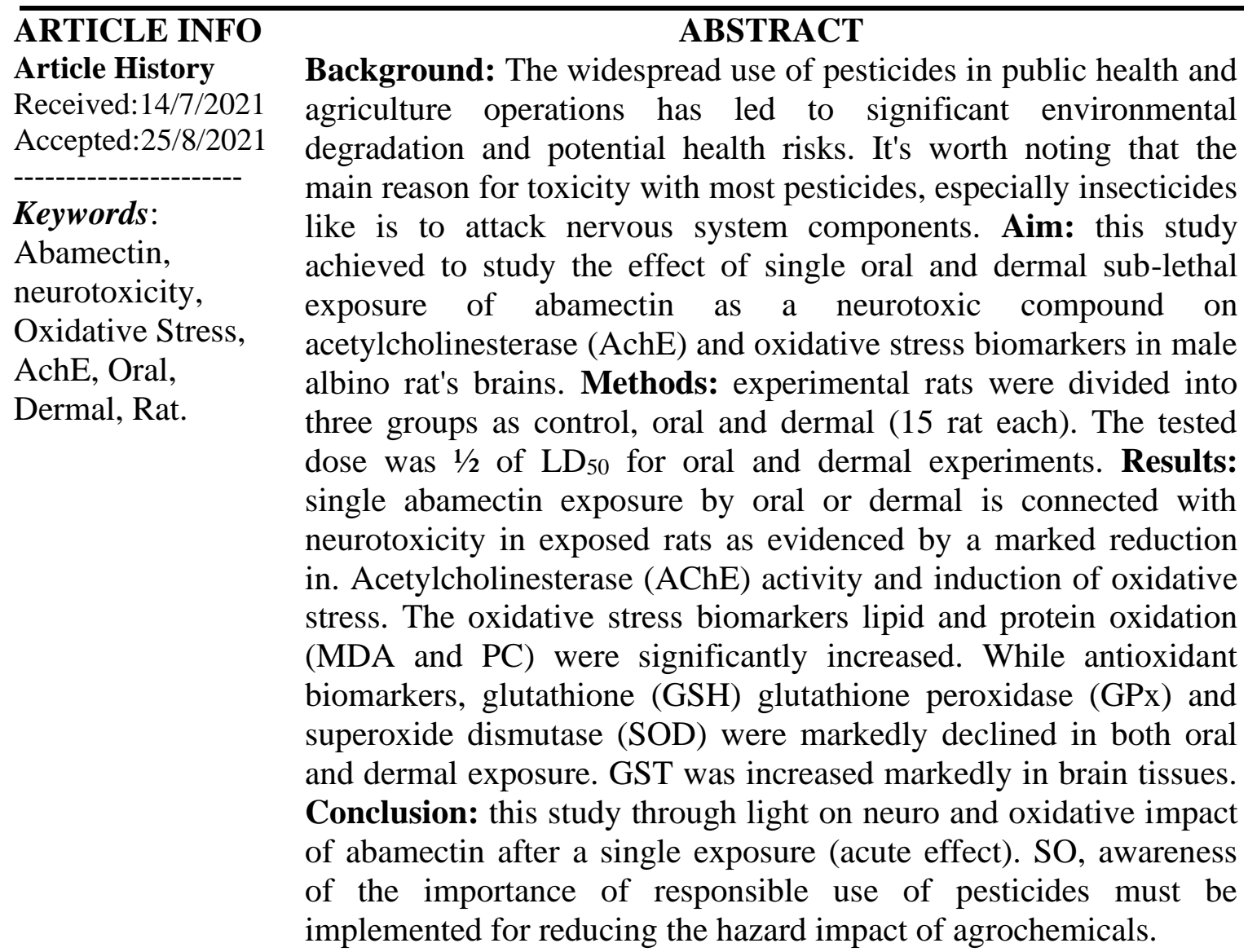

\section{INTRODUCTION}

Bio-pesticides among other agrochemicals are widely employed in agriculture to eradicate pests that destroy crops and promote sustainable development (Adu et al., 2019). These compounds have the potential to be harmful to some creatures, including persons, and therefore must be handled and safely disposed of (WHO, 2016). Pesticide exposure has been linked to cancer, neurologic and developmental problems, lung abnormalities (Mostafalou and Abdollahi, 2017), endocrine disruption (Maqbool et al., 2016; and Nascimento et al., 2018) systemic inflammation and immunological dysfunction in humans (Karami-Mohajeri and Abdollahi 2013; and Mokarizadeh et al., 2015). 
Studying the pathways of pesticide and metal impacts on the hematological, biochemical, and immunological systems can aid in the prevention of long-term diseases in farmers and improve the quality of life for rural workers. Neurotoxic effects have been considered as the second most harmful pesticide toxicity. It's worth noting that the main reason for toxicity with most pesticides, especially insecticides like is to attack nervous system components (Abdollahi and Karami-Mohajeri 2012; and KaramiMohajeri et al., 2013).

The widespread use of pesticides in public health and agriculture operations has led to significant environmental degradation and potential health risks. Pesticides' toxicity varies depending on the types of exposure, such as dermal, oral, or inhalation exposure. Aware of the harmful nature of the chemical, the risk of pesticide exposure tends to grow with dose (concentration) and basic durations. (Meenakshi et al., 2012). Exposure to pesticides can occur in a variety of ways, including technical jobs the manufacturing, distribution, application, and use of agricultural chemicals. Sudden incidents are another common source of contamination for applicators, and the rates of exposure associated with these events can have both short- and long-term health consequences (MacFarlane et al., 2013)

The most frequently used substance, abamectin which is used for both agricultural and medicinal objectives and has attracted interest due to its high toxicity to non-target species. (Bai and Ogbourne, 2016). Abamectin is a very potent and a key component of many public health services aimed at preventing the spread of lymphatic filarial illness and ultimately eliminating it worldwide. (Nasr et al., 2016). Due to its strong lipophilic nature, abamectin has been found to aggregate at elevated amounts in fatty tissue, such as the liver and fat (Gonzalez et al., 2009). Insects are harmed by abamectin, and mammals may be affected by it. abamectin poisoning destroyed 57 calves over the course of four years. Because the severity of intoxication symptoms varies, many animals recover quickly. This is thought to be due to an incorrect dosage given to the animals (Castanha Zanoli et al., 2012). Using a commercial formulation, researchers discovered indications of abamectin liver damage, including increased AST activity in rats, fed doses corresponding to $1 / 10$ or $1 / 100$ of the $\operatorname{LD}_{50}(18 \mathrm{mg} / \mathrm{kg})$ in the diet for 30-days (Eissa and Zidan, 2010).

Acetylcholinesterase (AChE) has been employed as a biomarker for pesticide toxicity. This enzyme is required for the proper functioning of the human central nervous system. It's in the responsibility of precise regulation, modulation of neurotransmitter release, and the acetylcholine hydrolysis process at cholinergic synapses, as well as identifying environmental pollutants. Anticholinesterase chemicals like organophosphorus pesticides and carbamate, as well as several toxic substances, suppress AChE, making it an acceptable enzymatic biomarker of neurotoxicity. (Zhao et al., 2015).

On a molecular scale, toxicants trigger a range of cytotoxicity pathways, including oxidative stress appearing to be the common element, leading to damage to cellular membrane lipids, DNA, and proteins. As well as antioxidant enzyme modification are likely to induce injury to any kind of molecule inside the cell, such as polyunsaturated fatty acids, glutathione, certain amino acids, and so on, due to their high reactivity (Poljšak and Fink 2014). Oxidative stress is a key factor in avermectins-induced cytotoxicity (Zhu et al., 2013). Oxidative stress, immunological damage, cytotoxicity and genotoxicity induced by abamectin in mammals, birds and fish (Huang et al., 2019 and Srivastava, et al., 2020). 
So, the aim of this study is to identify the impact of bio-pesticides (abamectin) through dermal or oral exposure on acetylecholinesterase and oxidative stress biomarkers in brain tissues of male albino rats during the acute toxicity period.

\section{MATERIALS AND METHODS Insecticide:}

A commercial formulation of abamectin (1.8\% EC) was supplied by Central Agricultural of Pesticides Laboratory (CAPL), Agricultural Research Centre (ARC), Dokki, Giza, Egypt.

\section{Experimental Design:}

Forty-five rats aged 3-4 months and weighing 160-180 $\mathrm{g}$ were purchased from the breeding unit of the Mammalian and Aquatic Toxicology Department, CAPL, ARC, Dokki, Giza, Egypt. The rats were kept in polypropylene cages with five rats per cage and allowed to acclimatize for one week under normal conditions of $20-25^{\circ} \mathrm{C}$, percent relative humidity (50$55 \%$ ), and a 12/12 $\mathrm{h}$ photoperiod (light/dark cycles). The rats were given unlimited access to a normal pellet diet and water. The animals were divided into three groups, randomly (15 rats each). The first group of 10 rats acted as a control group, getting no treatments. oral exposure was performed on the second group at the dose of $10 \mathrm{mg} / \mathrm{kg}\left(1 / 2 \mathrm{LD}_{50}\right)$. While the third group was treated with cutaneous exposure at the dose of $150 \mathrm{mg} / \mathrm{kg}(1 / 2$ $\mathrm{LD}_{50}$ ). The trunks (10 percent of the skin surface) of the experimental rats are clipped using electric clippers (Oster Corp., Model A2, Milwaukee, WI, USA) before 24 hours of the dermal exposure of insecticide The trunk of the animal treated with abamectin is wrapped with gauze and rubber damming. The gauze is removed twenty-four hours after application of

\section{RESULTS}

\section{Abamectin and Neurotoxic Biomarker Acetylcholinesterase (AchE):}

The results (Table, 1) showed an increase significantly $(\mathrm{p} \leq 0.001)$ in $\mathrm{AChE}$ activity in the rat's brain treated with insecticide, and the treated sites are washed with sterile distilled water. Daily observations and responses are documented for 14 days. the rats are euthanized by decapitation after 1,7 and 14 days of treatment to obtain the brain which is washed with cold saline buffer and immediately stored at $-80{ }^{\circ} \mathrm{C}$. This study was conducted in accordance with ethical procedures and policies approved by the Institutional Animal Care and Use Committee of Zagazig University (No. ZUIACUC/2/F/38/2019).

\section{Tissue Preparation:}

The brain tissues were homogenised in an ice-cold $50 \mathrm{mM}$ sodium phosphate buffer ( $\mathrm{pH} \mathrm{7)}$ with 0.1 $\mathrm{mM}$ ethylendiaminetetraacetic acid (EDTA), giving a $10 \%$ (W/V) homogenate. The homogenates were spun for 30 minutes at $4^{\circ} \mathrm{C}$ at $12.000 \mathrm{rpm}$. the supernatant was collected and utilized to investigate enzyme activity.

\section{Neurological and Oxidative Stress Biomarkers Assay:}

Acetylcholinesterase (AChE) activity was assayed in liver tissues by the method of Ellman, et al., (1961). Total protein (TP) level was quantified by the procedure of Bradford (1976). Lipid peroxidation was estimated as the concentration of thiobarbituric acid reactive products (malondialdehyde, MDA) (Ohkawa, et al., 1979). Protein carbonyl (PC) content was assayed using the mentioned method Yan et al., (1995). Superoxide dismutase (SOD) and glutathione -S- transferees (GST) activity was measured by the methods of Marklund and Marklund, (1994) and Habig, et al., (1973) respectively. Total reduced glutathione (GSH) content and glutathione peroxidase activity were measured by Beutler, et al., (1963) method.

abamectin by oral and dermal compared to the untreated group after 1 day of treatment. However, AChE inhibited significantly $(\mathrm{p} \leq 0.001)$ after 7 and 14 days of exposure to abamectin dermally. 
Table (1): Abamectin and acetylecholinesterase (AchE) as a neurotoxic biomarker.

\begin{tabular}{|c|c|c|c|c|c|}
\hline Biomarkers & E.R. & Control & 1-day & 7-Days & 14-Days \\
\hline \multirow{2}{*}{$\begin{array}{c}\text { AChE } \\
(\mathbf{n m o l} / \mathbf{m i n} / \mathbf{m g} \text { pro })\end{array}$} & D.E. & $\mathbf{6 1 7 . 1 7} \pm 23.4$ & $\mathbf{7 8 7 . 4 0} \pm 26.08^{* * * *}$ & $\mathbf{4 1 7 . 1 7} \pm 13.78^{* * * *}$ & $\mathbf{4 1 3 . 8 7} \pm 14.83^{* * * *}$ \\
\cline { 2 - 4 } & O.E. & & $\mathbf{7 0 4 . 0 8} \pm 16.59^{* *}$ & $\mathbf{5 2 7 . 8 8} \pm 19.20^{* *}$ & $\mathbf{6 1 9 . 0 1} \pm 21.68$ \\
\hline
\end{tabular}

E.R.: Exposure Route, D.E.: Dermal Exposure, and O.E.: Oral Exposure. Data expressed as mean \pm S.E.

$*$ : Significant at $0.05, * *$, Significant at 0.01: and ***: Significant at 0.005 .

\section{Abamectin and Oxidative Stress Biomarkers:}

A significant increase in brain MDA levels was noticed in all groups $(\mathrm{p} \leq$ 0.001) except, a significantly decreased after 1 and 14 days from treatment with a single dose by dermal and oral respectively, was observed. In addition, there was a significant increase in brain PC levels in groups treated with a sublethal dose of abamectin by gavage and topical after all periods of exposure compared to the untreated group ( $\mathrm{p} \leq$ 0.001). Moreover, a significant increase in brain glutathione (GSH) content was seen in orally treated with abamectin after 7 days of exposure compared to the control group while a significant decrease was observed after dermal exposure after 7 and 14 days of treatment and after 14 days orally treated with abamectin (Table 2).

Table (2): Abamectin and oxidative stress biomarkers (MDA, PC and GSH)

\begin{tabular}{|c|c|c|c|c|c|}
\hline Biomarkers & E.R. & Control & 1-day & 7-Days & 14-Days \\
\hline \multirow{2}{*}{$\begin{array}{c}\text { MDA } \\
(\mu \mathrm{mol} / \mathrm{mg} \text { pro })\end{array}$} & D.E. & \multirow{2}{*}{$\mathbf{1 7 . 8 7} \pm 0.77$} & $\mathbf{1 8 . 5 7} \pm 0.66$ & $47.48 \pm 1.44^{* * *}$ & 24.27 $\pm 0.64^{* * *}$ \\
\hline & O.E. & & 26.49 $\pm 0.79^{* * * *}$ & $19.47 \pm 0.49$ & $20.75 \pm 3.0 .3^{* * *}$ \\
\hline \multirow{2}{*}{$\begin{array}{c}\text { PC } \\
\text { (nmol /mg pro) }\end{array}$} & D.E. & \multirow{2}{*}{$29.38 \pm 1.13$} & $56.11 \pm 1.3^{* * *}$ & $62.27 \pm 1.34^{* * *}$ & $\mathbf{3 8 . 5 6} \pm 0.92^{* * *}$ \\
\hline & O.E. & & $67.95 \pm 2.38^{* * *}$ & 56.03 $\pm 0.65^{* * *}$ & 40.21 $\pm 1.12^{* * *}$ \\
\hline \multirow{2}{*}{$\begin{array}{c}\text { GSH } \\
\text { (nmol/mg pro) }\end{array}$} & D.E. & \multirow{2}{*}{$\mathbf{4 . 4 1} \pm 0.04$} & $4.27 \pm 0.08$ & $4.31 \pm 0.16^{*}$ & $3.66 \pm 0.14^{* * *}$ \\
\hline & O.E. & & $\mathbf{5 . 4 3} \pm 0.13^{\text {*** }}$ & 4.39 \pm 0.14 & $\mathbf{3 . 4 5} \pm 0.14^{* * *}$ \\
\hline
\end{tabular}

E.R.: Exposure Route, D.E.: Dermal Exposure, and O.E.: Oral Exposure. Data expressed as mean \pm S.E.

$*$ : Significant at $0.05, * *$, Significant at 0.01: and ***: Significant at 0.005 .

\section{Abamectin and Antioxidant Enzymes Biomarkers:}

A significant decrease in the activities of brain GPx was observed among rats treated with abamectin $(\mathrm{p} \leq$ 0.001 ) by the two routes of exposure after all periods compared to the control group. The activity of SOD was inhibited significantly after oral exposure with abamectin during the study periods. However, SOD significantly increased after 1 day of dermal treatment. GST activity was statistically increased in rat's brain treated dermally with abamectin after all periods and after 1 day in the group treated orally with abamectin (Table $3)$.

Table (3): Abamectin and antioxidant enzymes biomarkers (GP, SOD and GST)

\begin{tabular}{|c|c|c|c|c|c|}
\hline Biomarkers & E.R. & Control & 1-day & 7-Days & 14-Days \\
\hline \multirow{2}{*}{$\begin{array}{c}\mathbf{G P}_{\mathbf{X}} \\
(\mathrm{nmol} / \mathrm{min} / \mathrm{mg} \text { pro })\end{array}$} & D.E. & \multirow{2}{*}{$14.13 \pm 0.28$} & $12.73 \pm 0.0 .36^{* * * *}$ & $12.19 \pm 0.37^{* * * *}$ & $13.95 \pm 0.0 .29^{* * * *}$ \\
\hline & O.E. & & $10.16 \pm 0.28^{* * * *}$ & $\mathbf{1 0 . 2} \pm 0.31^{* * *}$ & $14.13 \pm 0.16$ \\
\hline \multirow{2}{*}{$\begin{array}{c}\text { SOD } \\
(\mathrm{U} / \mathrm{mg} \mathrm{pt})\end{array}$} & D.E. & \multirow{2}{*}{$\mathbf{4 . 4 1} \pm 0.1$} & $\mathbf{4 . 8 0} \pm 0.0 .07^{* *}$ & $4.21 \pm 0.0 .12$ & $\mathbf{4 . 6 3} \pm 0.04$ \\
\hline & O.E. & & $3.74 \pm 0.12$ & $3.67 \pm 0.04^{* * *}$ & $3.95 \pm 0.0 .06^{* * * *}$ \\
\hline \multirow{2}{*}{$\begin{array}{c}\text { GST } \\
(\mathrm{nmol} / \mathrm{min} / \mathrm{mg} \text { pro })\end{array}$} & D.E. & \multirow{2}{*}{$\mathbf{8 . 5 1} \pm 0.0 .37$} & $12.27 \pm 0.50^{* * *}$ & $\mathbf{1 0 . 8 0} \pm 0.18^{* *}$ & $17.20 \pm 0.70^{* * *}$ \\
\hline & O.E. & & $9.48 \pm 0.10^{*}$ & $8.67 \pm 0.28$ & $9.23 \pm 0.21$ \\
\hline
\end{tabular}

E.R.: Exposure Route, D.E.: Dermal Exposure, and O.E.: Oral Exposure. Data expressed as mean \pm S.E.

$*$ : Significant at $0.05, * *$, Significant at 0.01 : and ***: Significant at 0.005 . 


\section{DISCUSSION}

Human exposure to pesticides can happen in many different ways, which include workers who perform pesticide manufacturing, transportation, delivery, and application. Residing in areas with high contaminants, pesticide can buildup in the food chain (Mostafalou and Abdollahi 2017)

Farmers who used agrochemicals were typically less aware of the negative health consequences of these chemicals, which might be explained by their lower educational level compared to the general population (Damalas and Eleftherohorinos, 2011). Pesticides from different chemical families, such as pyrethroids, triazines, and paraquat, might have an impact on $\mathrm{AChE}$ activity. (Lionetto et. al., 2013). As a result, AChE might be employed as an indication of exposure in the long-term monitoring of individuals exposed to pesticides other than organophosphate and carbamate (Hernandez et al., 2005). Cell proliferation, maturation, and responsiveness to numerous insults, including stress affected by AchE activity. Also, it carries out an important role in non-enzymatic, trophic such as stimulation of neurogenesis and remodelling and neuromodulatory such promotion of longterm functional alterations in the central nervous system (Vučević et al., 2009). The increase in AchE activity following both types of abamectin exposure after 1 day may be ascribed to an increase in Ach release by impacting sodium channels in cholinergic neurons, where abamectin, such as lindane, impacts GABA neurotransmitter synthesis (Vučević et al., 2009). Malathion also results in an increase in hippocampal and cortical AchE activity after only a shorter time of exposure (Trevisan et al., 2008).

$$
\text { Increased amounts of }
$$
polyunsaturated fatty acids (PUFAs) in neuronal membranes also correlate to a higher oxygen consumption which results in the oxidative degradation of polyunsaturated fatty acids found in cellular membranes. Their decomposition results in the production of cytotoxic and reactive malondialdehyde (MDA) that may disperse from its source to attack distant targets and form covalent connections with a variety of molecules. MDA also induced mitochondrial dysfunction in neurons by directly the production of reactive oxygen species (ROS) and altering mitochondrial proteins (Long et al., 2009). Malondialdhyde (MDA) has been recognized as a redox status biomarker and is now regarded as a late oxidative stress biomarker end product (López et al., 2007). MDA has a greater reactivity for nucleophiles such amino acids or protein) where, secondary detrimental reactions are induced by biomolecule interactions, resulting in biochemical changes (Ayala, et. al., 2014). The aggregation of modified or oxidized proteins in the brain causes the release of reactive oxygen species (ROS) and mitochondrial dysfunction, both of which are associated with neurodegeneration (Liu, et. al., 2017). Protein oxidation concludes specific amino acid modification, peptide cleavage and protein cross-linkage. Protein modification affects signal transduction, enzymes activity and proteolysis. (Kaur and Thakur, 2018).

Because pesticides may penetrate into the circulatory more rapidly through to the stomach than through the skin, the oral $\mathrm{LD}_{50}$ is relatively low than the dermal LD $_{50}$ (Nesheim et al., 2008). Furthermore, adjuvant substances used in pesticides to enhance biological functions as well as simplify implementation may reach target species contributing to the overall effect of pesticide exposure (Surgan et al., 2010). These $\mathrm{LD}_{50}$ values, on the other hand, must be adjusted to account for the concentration of the pesticide formulation in use. This is because the formulation has a major impact on the actual toxicity of a commercial pesticide product. For example, when a very toxic pesticide is 
produced as an emulsifiable concentrate rather than a microcapsule solution, it becomes much more toxic (Damalas and Eleftherohorinos, 2011).

These findings are consistent with those of Nasr et al. (2016) who demonstrated that the brain antioxidant machinery was unable to counteract ABMinduced oxidative stress (SOD and CAT were dramatically decreased in rats treated with $\mathrm{CPF}, \mathrm{ABM}$, or both) attributable to the brain's high oxidative metabolism (Gandhi and Abramov, 2012). Furthermore, Li et al., (2013) found that when the concentration of avermectin increased, the activities of SOD and CAT in the cerebellum decreased. Suppression of the free radical-scavenging SOD and CAT enzymes resulted in a buildup of superoxide, which enhanced lipid peroxidation and DNA modulation, disrupted gene expression, and cellular damage (Calviello et al., 2006). Glutathione peroxidase (GSH-Px) is a wide class of selenium-containing enzymes that detoxify different peroxides by using the reduced form of glutathione as an electron donor. The availability of reduced glutathione and selenium levels is required for GSH-Px function GSH-Px has the biological function of reducing the transformation of lipid hydroperoxides to their corresponding alcohols, as well as reducing free $\mathrm{H}_{2} \mathrm{O}_{2}$, protecting the tissue from oxidative damage (Baba et al.,2016). The oxidative stress induced by abamectin intoxication may be related to the ability of abamectin to induce mitochondrial dysfunction and disturbance of calcium homeostasis (Maioli et al., 2013). These results are similar to those found by Zhu et al., (2013) and Li et al., (2013). Whereas, avermectin caused liver damage, inhibition of SOD, and increased MDA levels. abamectin appears to have a significant impact on the expression of GABA receptors in rat brain tissue. macrocyclic lactones have a high affinity for glutamategated $\mathrm{Cl}$ Channels in neuronal cells localized to the CNS (McCavera et al.,
2007). Excessive chloride ions overburden the postsynaptic neuron, causing membrane hyperpolarization and inhibiting nerve signal transmission (Novelli et al., 2012).

Finally, Integrated Crop Management (ICM), worker and product safety, usage of low acute and chronic toxicity pesticides, optimum formulation, safe packaging, simple application technique, and extended storage stability are all factors to consider in pesticides application for controlling the health hazards induced by pesticides (Chandler et al., 2008)

\section{REFERENCES}

Abdollahi M, Karami-Mohajeri S (2012):

A comprehensive review on experimental and clinical findings in intermediate syndrome caused by organophosphate poisoning. Toxicology and Applied Pharmacolology, 258:309-314.

Adu P, Forkuo EK Issah A, Asumadu IO, Cadman-Sackey E, Quarshie AAA, Gyabaa $S$ and., Epharaim RKD (2019): High incidence of moderately reduced renal function and lead bioaccumulation in agricultural workers in assin south district, Ghana: a community-based casecontrol study. International Journal of Nephrology, 5368427

Ayala, A.; Muñoz, M. and Argüelles, S. (2014): Lipid Peroxidation: Production, Metabolism, and Signaling Mechanisms of Malondialdehyde and 4-Hydroxy2- Nonenal. Oxidative Medicine and Cellular Longevit, Article ID 360438, 31 pages.

Baba, N Raina, R, Verma, P, Sultana M (2016): Free radical-induced nephrotoxicity following repeated oral exposure to chlorpyrifos alone and in conjunction with fluoride in rats. Turkish Journal of Medical Science, 46: 512-517

Bai, SH and Ogbourne, S (2016): Ecotoxicological effects of the 
avermectin family with a focus on abamectin and ivermectin. Chemosphere, 154, 204-214

Beutler E, Olga D and Kelly M (1963): Improved method for determination of blood glutathione: from the department of medicine, City of Hope medical Centre. Journal of Laboratory and Clinical Medicine, 61: 882 - 888.

Bradford MM (1976): A rapid and sensitive method for the quantitation of microgram quantities of protein utilizing the principle of protein-dye binding. Analytical Biochemistry, 72 (1-2): 248 - 254.

Calviello, G, Piccioni, E, Boninsegna, A, Tedesco, B, Maggiano, N, Serini, S, Wolf, FI and Palozza P (2006) DNA damage and apoptosis induction by the pesticide Mancozeb in rat cells: involvement of the oxidative mechanism. Toxicology and Applied Pharmacolology, 211:87-9

Chandler, D; Davidson, G; Grant, WP; Greaves, J; Tatchell, GM (2008): Microbial biopesticides for integrated crop management: An assessment of environmental and regulatory sustainability. Trends in Food Science\&Technology, 2008, 19, 275-283.

Castanha Zanoli, JC; Maioli, MA; Medeiros, HCD. and Mingatto FE (2012): Abamectin affects the bioenergetics of liver mitochondria: A potential mechanism of hepatotoxicity. Toxicology in Vitro, 26: 51-56

Damalas, CA. and Eleftherohorinos IG (2011): Pesticide Exposure, Safety Issues, and Risk Assessment Indicator International. Journal. Environmental Research and. Public Health, 8, 1402-1419; doi:10.3390/ijerph8051402

Eissa, FI and Zidan, NA (2010): Haematological, biochemical and histopathological alterations induced by abamectin and Bacillus thuringiensis in male albino rats. Acta Biologica Hungarica, 61, 3344.

Ellman GL, Courtney K D, Andres VJ and Featherstone RM (1961): A new and rapid colorimetric determination of acetyl cholinesterase activity. Biochemical Pharmacology, 7: 88 95.

El-Shenawy andNahla, S. (2010): Effects of insecticides fentrithion, endosulfan and abamectin on antioxidant parameters of isolated rat hepatocytes. Toxicology In Vitro, 24:1148-1157

Gandhi, S and Abramov, AY (2012): Mechanism of oxidative stress in neurodegeneration. Oxidative Medicine and Cellular Longevity2012, 428010.

Gonzalez A, Sahagun A, Diez MJ, Fernandez N, Sierra M, and Garcia JJ (2009): The pharmacokinetics and metabolism of ivermectin in domestic animal species. The Veterinary Journal, 179 (1): 25 37.

Habig WH, Pabst MJ and Jacoby WB (1973): Glutathione - S transferees: the first step in mercapturic fermentation. The Journal of Biochemistry, 249 (22): 7130 - 7139.

Hernandez, AF, opez, OL, Rodrigo L, et al., (2005): Changes in', erythrocyte enzymes in humans long-term exposed to pesticides: influence of several markers of individual susceptibility Toxicology Letters, vol. 159, no. 1, pp. 13-21, 2005.

Huang Y, Yuhang H, Zhiqiu H, Jilei Z, and Qiang H (2019): Avermectin induces the oxidative stress, genotoxicity, and immunological responses in the Chinese Mitten Crab, Eriocheirsinensis. PLOS 
ONE, 14(11): e0225171.

Karami-Mohajeri $\mathrm{S}$ and Abdollahi $\mathrm{M}$

(2013): Mitochondrial dysfunction and organophosphorus compounds. Toxicology and Applied Pharmacolology, 270(1): 39-44.

Karami, S, Andreotti, G, Koutros, S, Hughes Barry, K, Moore, LE, Han, S, Hoppin, JA, Sandler, DPH, Lubin, J, Burdette, LA, Yuenger, J,Yeager, M, Freean LEB, Blair, A and Alavanja MCR(2013): Pesticide exposure and inherited variants in vitamin $d$ pathway genes in relation to prostate cancer. Cancer Epidemiology Biomarkers \&Prevention, 22:1557-1566.

Kaur R. and Thakur Y. (2018): Diseases caused by pesticide induce oxidative stress- A Review. Journal of Emerging Technologies and Innovative Research, 5 (8): 325-331.

Li M, Tian-Zi Y, Wen-Jun Z, Jian-Ping Q, Ci Liu, Bing Z, Shi-Wen $X$ and Shu L (2013). Antioxidant response and histopathological changes in brain tissue of pigeon exposed to avermectin. Ecotoxicology, 22: 1241-1254.

Lionetto, MG, Caricato, R Calisi, A, Giordano, ME, and Schettin $\mathrm{T}$ (2013): Acetylcholinesterase as a Biomarker in Environmental and Occupational Medicine: New Insights and Future Perspectives

Liu, Z.; Zhou, T.; Ziegler, A. C.; Dimitrion, P. and Zuo, L. (2017): Oxidative Stress in Neurodegenerative Diseases: From Molecular Mechanisms to Clinical Applications. Oxidative Medicine and Cellular Longevity, Article ID 2525967, 11 pages

Long, J, Liu, C, Sun, L, Gao, H, Liu, J (2009) Neuronal mitochondrial toxicity of malondialdehyde Inhibitory effects on respiratory function and enzyme activities in rat brain mitochondria.
Neurochemical. Research, 34:786794.

López, O.; Hernández, A. F.; Rodrigo, L.; Gil, F.; Pena, G.; Serrano, J. L. and Pla, A. (2007): Changes in antioxidant enzymes in humans with long-term exposure to pesticides. Toxicology letters, 171(3): 146 - 153.

Macfarlane, E, Carey, R, Keegel, T, ElZaemay,S and Fritschi, L(2013): Dermal exposure associated with occupational end use of pesticides and the role of protective measures. Safety and Health at Work,4(3), 136-141; DOI: 10.1016/j.shaw. 201 3.07.004.

Maioli MA, de Medeiros HC, Guelfi M, Trinca V, Pereira FT, Mingatto FE (2013): The role of mitochondria and biotransformation in abamectin-induced cytotoxicity in isolated rat hepatocytes. Toxicology In Vitro, 27 (2): 570-579.

Maqbool F, Mostafalou S, Bahadar H and Abdollahi M (2016) Review of endocrine disorders associated with environmental toxicants and possible involved mechanisms. Life Science, 145:265-273.

Marklund SL and Marklund G (1994): Involvement of the superoxide anion radical in the autoxidation of pyrogallol and a convenient assay for superoxide dismutase. European Journal of Biochemistry, 47 (3): 469 - 474.

McCavera, S, Walsh, TK, Wolstenholme, AJ (2007): Nematode ligand-gated chloride channels: an appraisal of their involvement in macrocyclic lactone resistance and prospects for developing molecular markers. Parasitology, 134, 1111-1121.

Meenakshi, SP, Bhawana, M, Anita S, Gothecha VK (2012): A short review on how pesticides affect human health. International Journal of Ayurvedic and Herbal Medicine, 2 (5): 935-946. 
Mokarizadeh A, Faryabi MR, Rezvanfar MA and Abdollahi M (2015): A comprehensive review of pesticides and the immune dysregulation: mechanisms, evidence and consequences. Toxicology Mechanisms and Methods, 25(4):258-278.

Mostafalou S and Abdollahi M (2017): Pesticides: an update of human exposure and toxicity. Archives of Toxicology, 91 (2):549-599

Nascimento S, Göethel G, Gauer B, Sauer E, Nardi J, Cestonaro L, Correia D, Peruzzi C, Mota L, Machry RV, Furlanetto TW, Saint'Pierre T, Gioda A, Arbo MD and Garcia SC (2018): Exposure to environment chemicals and its possible role in endocrine disruption of children from a rural area. Environmental Research, 167:488-498.

Nasr, HM, El-Demerdash FM and ElNagar WA (2016): Neuro and renal toxicity induced by chlorpyrifos and abamectin in rats Toxicity of insecticide mixture. Environmental Science and Pollution Research, (2016) 23:1852-1859

Nesheim, ON; Fishel, FM; Mossler, M (2008): Toxicity of Pesticides; Pesticide Information Office, Food Science and Human Nutrition Department, Florida Cooperative Extension Service, Institute of Food and Agricultural Sciences, University of Florida: Gainesville, FL, USA, 2008; p. 7.

Novelli, A, Vieira, BH, Cordeiro, D, Cappelini, LT, Vieira, EM, Espindola, EL (2012): Lethal effects of abamectin on the aquatic organisms Daphnia similis, Chironomus xanthus and Danio rerio. Chemosphere, 86, 36-40.

Ohkawa H, Ohishi N and Yagi K (1979): Assay for lipid peroxides in animal tissues by thiobarbituric acid reaction. Analytical Biochemistry, 95: 351 - 358.
Poljšak B and Fink R (2014): Review Article: The Protective Role of Antioxidants in the Defence against ROS/RNS-Mediated Environmental Pollution. Oxidative Medicine and Cellular Longevity, Volume 2014, Article ID 671539, 22 pages

Srivastava PK, Singh VP, Singh A, Singh S, Prasad SM, Tripathi DK and Chauhan DK (2020): Pesticides in Crop Production: Physiological and Biochemical Action. Wiley Online Library: Hoboken, NJ, USA.

Surgan, M, Condon, M and Cox, C (2010) Pesticide risk indicators: Unidentified inert ingredients compromise their integrity and utility. Environmental. Management, 2010, 45, 834-841.

Trevisan R, Uliano-Silva M, Pandolfo P, Franco JL, Brocardo PS, Santos ARS., Farina M, Rodrigues ALS, Takahashi RN, Dafre AL (2008): Antioxidant and acetylcholinesterase response to repeated malathion exposure in rat cerebral cortex and hippocampus. Basic Clinical. Pharmacolology and. Toxicology, 102, 365-369

Vučević, D. Petronijević, N Radonjić, N, Rašić-Marković A, Mladenović D, Radosavljević T, Hrnčić D, Djurić, $D$ Šušić V , Djuro $M$ and Stanojlović $\quad \mathrm{O}(2009)$ : Acetylcholinesterase as a potential target of acute neurotoxic effects of lindane in rats. General Physiology and Biophysics, (2009), Special Issue, 28, 18-24

WHO: World Health Organization (2016) Health Topics-Pesticides.

Yan LJ, Traber MG and Packer L (1995): Spectrophotometric method for determination of carbonyls in oxidative modified apolipoprotein B of human low-density lipoproteins. Analytical Chemistry, 228 (2): 349 - 351.

Zhao H, Ji X, Wang B, Wang N, Li X, Ni R, Ren, J (2015): An ultra-sensitive 
acetylcholinesterase biosensor Zhu, WJ, Li, M, Liu, C, Qu, JP, Min, YH, based on reduced graphene Oxide- $\quad \mathrm{Xu}, \quad \mathrm{SW}$ and $\mathrm{Li} S \mathrm{~S}$ (2013): $\mathrm{Au}$ nanoparticles-b-cyclodextrin/ Avermectin induced liver injury in Prussian blue-chitosan nanocomposites for organophosphorus pesticides detection. Biosensors and bioelectronics, 65, 23-30. pigeon: mechanisms of apoptosis and oxidative stress. Ecotoxicology and. Environmental. Safety, 98, 74-81. 